\title{
Article
}

\section{Influence of Infill Patterns Generated by CAD and FDM 3D Printer on Surface Roughness and Tensile Strength Properties}

\author{
Mohammadreza Lalegani Dezaki ${ }^{1,2} \oplus$, Mohd Khairol Anuar Mohd Ariffin ${ }^{1} \oplus$, Ahmad Serjouei ${ }^{2} \oplus$, \\ Ali Zolfagharian ${ }^{3}\left(\mathbb{D}\right.$, Saghi Hatami ${ }^{4}$ and Mahdi Bodaghi ${ }^{2, *} \mathbb{D}$ \\ 1 Advance Manufacturing Research Group, Department of Mechanical and Manufacturing Engineering, \\ Universiti Putra Malaysia, Serdang 43400, Malaysia; lalegani.mr@gmail.com (M.L.D.); \\ khairol@upm.edu.my (M.K.A.M.A.) \\ 2 Department of Engineering, School of Science and Technology, Nottingham Trent University, \\ Nottingham NG11 8NS, UK; ahmad.serjouei@ntu.ac.uk \\ 3 School of Engineering, Deakin University, Geelong 3216, Australia; a.zolfagharian@deakin.edu.au \\ 4 Department of Industrial Engineering, University of Applied Science and Technology, \\ Tehran 1599665111, Iran; saghihatami633@gmail.com \\ * Correspondence: mahdi.bodaghi@ntu.ac.uk
}

\section{check for} updates

Citation: Lalegani Dezaki, M.; Ariffin, M.K.A.M.; Serjouei, A.; Zolfagharian, A.; Hatami, S.; Bodaghi, M. Influence of Infill Patterns Generated by CAD and FDM 3D Printer on Surface Roughness and Tensile Strength Properties. Appl. Sci. 2021, 11, 7272. https://doi.org/ 10.3390/app11167272

Academic Editors: Anming $\mathrm{Hu}$ and Daniel X.B. Chen

Received: 27 June 2021

Accepted: 1 August 2021

Published: 7 August 2021

Publisher's Note: MDPI stays neutral with regard to jurisdictional claims in published maps and institutional affiliations.

Copyright: (c) 2021 by the authors. Licensee MDPI, Basel, Switzerland. This article is an open access article distributed under the terms and conditions of the Creative Commons Attribution (CC BY) license (https:/ / creativecommons.org/licenses/by/ $4.0 /)$.

\begin{abstract}
Fused deposition modeling (FDM) is a capable technology based on a wide range of parameters. The goal of this study is to make a comparison between infill pattern and infill density generated by computer-aided design (CAD) and FDM. Grid, triangle, zigzag, and concentric patterns with various densities following the same structure of the FDM machine were designed by CAD software (CATIA V $5^{\circledR}$ ). Polylactic acid (PLA) material was assigned for both procedures. Surface roughness (SR) and tensile strength analysis were conducted to examine their effects on dog-bone samples. Also, a finite element analysis (FEA) was done on CAD specimens to find out the differences between printing and simulation processes. Results illustrated that CAD specimens had a better surface texture compared to the FDM machine while tensile tests showed patterns generated by FDM were stronger in terms of strength and stiffness. In this study, samples with concentric patterns had the lowest average SR (Ra) while zigzag was the worst with the value of $6.27 \mu \mathrm{m}$. Also, the highest strength was obtained for concentric and grid samples in both CAD and FDM procedures. These techniques can be useful in producing highly complex sandwich structures, bone scaffolds, and various combined patterns to achieve an optimal condition.
\end{abstract}

Keywords: additive manufacturing; polylactic acid; fused deposition modeling; FDM; PLA; $3 \mathrm{D}$ printing

\section{Introduction}

The most common and environment-friendly additive manufacturing (AM) process is fused deposition modeling (FDM) [1]. FDM has been widely used to 3D print highly complex products in domestic and industry sections [2,3]. As shown in Figure 1, the FDM machines consist of various components that are integrated to build parts quickly without wasting material and tooling [4-6]. The process is started by designing and developing the model in computer-aided design (CAD) software packages. Subsequently, the prepared file must be changed into a readable format by FDM 3D printers. The usable format is known as standard triangle language (STL) and exclusive software packages are required to convert the CAD file into STL. The stepper motors feed and push the material, which exists in the shape of a solid filament, through the nozzle. The extruder melts the material at a specific temperature and deposits the molten material on the platform. The molten material solidifies quickly and sticks to the platform. Then, the printer follows numerical G-codes to repeat the procedure layer by layer $[7,8]$. 


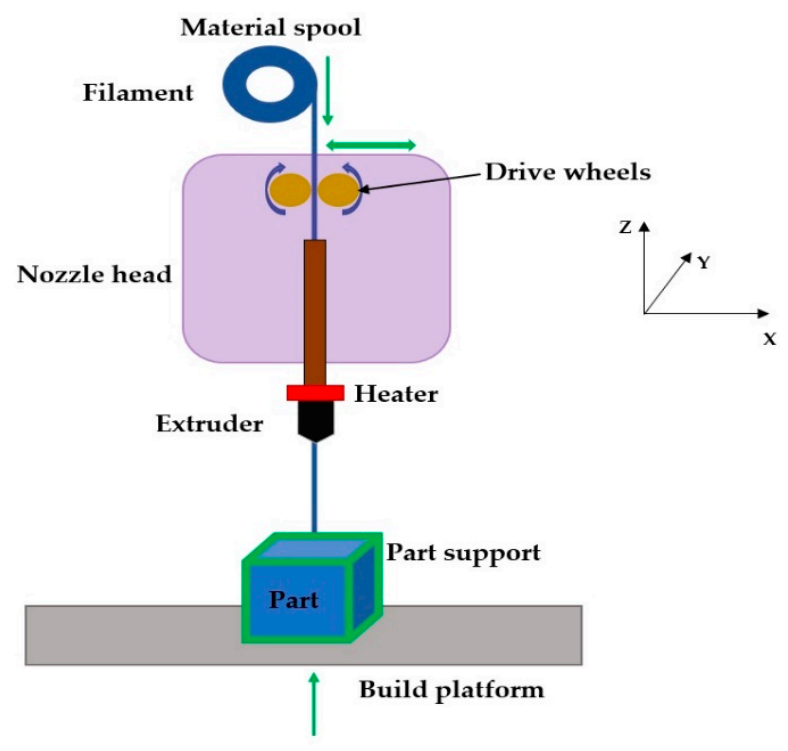

Figure 1. Schematic of FDM process.

A wide range of materials such as low-temperature metal alloys and composites can be used in the FDM but the main materials in this process are thermoplastics and polymer-based composites [9-11]. Achieving a satisfactory product with good mechanical properties is related to build orientation, infill pattern, infill density, nozzle temperature, nozzle diameter, printing speed, and layer thickness [12,13]. Non-optimal conditions and poor temperature lead to issues in printing procedures like warpage and shrinkage [13-15]. It should be noted that finding elongation at break, Young's modulus, and tensile strength are crucial for isotropic and anisotropic engineering plastics to enhance mechanical properties [16,17]. The drawback of the FDM process produces support structures to avoid material drops and tightens the gaps to have better binding [18]. However, the support structure influences surface texture and the quality of areas with supports attached to them becomes poor and rough [19]. Another defect in FDM printed parts is the staircase effect that happens due to the layer binding behavior [20]. The final quality of their products is also not as good as other technologies such as the MJ process [21,22].

Over the past few decades, many studies have been conducted on the FDM parameters to increase productivity and develop process capabilities [23-25]. Ziemian, et al. [26] found that the largest ultimate and yield strength of printed ABS400 was $93 \%$ of injection-molded parts at $0^{\circ}$ raster orientation [27]. Yang, et al. [28] using ANOVA, found that nozzle diameter and layer thickness parameters have the greatest effects on printing time, SR, and tensile strength $[29,30]$. Build orientation is an alternative factor that plays a crucial role because of its effects on surface texture, mechanical properties, dimensional accuracy, and printing time [31,32]. SR values (e.g., skewness $\left(S_{k u}\right)$, kurtosis $\left(R_{k u}\right)$, and average roughness $\left.\left(R_{a}\right)\right)$, printing time, and support structure were increased when the build angle was in perpendicular directions $\left(5^{\circ}\right.$ to $\left.85^{\circ}\right)$ [33]. Samples with $0^{\circ}$ orientation have the best surface texture compared to perpendicular and vertical specimens [34].

3D printed parts are hollow or solid from $0 \%$ to $100 \%$ and various patterns exist in the shape of linear, wiggle, honeycomb, triangle, etc. Finding an appropriate infill percentage and pattern generates strong parts with minimum weight [35]. Ćwikła, et al. [36] found that the strength and weight of printed samples were affected by the infill pattern and that honeycomb was the strongest among other patterns [37]. Flexural strength, tensile strength, and stiffness of products depend on the infill density, so when the infill density increases, the printed parts become stronger [38,39]. Gyroid, Schwarz D, and Schwarz P examined cylindrical bio-inspired patterns [40] with a slicing strategy and build inclination factor. A finite element analysis (FEA) via ANSYS ${ }^{\circledR}$ software was used based on the coefficient of variation (COV) when the extrusion angle was not aligned with the build angle [41]. 
Dave, et al. [42] determined that porosity in samples at $60 \%$ infill density had the lowest strength. Besides, concentric and rectilinear patterns indicated the highest tensile strength in three directions, namely, flat, on the long edge, and on short edges.

Moreover, Burke, et al. [43] investigated the influence of orientation, nozzle diameter, and infill percentage on SR in polylactic acid (PLA) samples. The lowest roughness with the value of $12.4 \mu \mathrm{m}$ was conducted for the flat angle, $0.2 \mathrm{~mm}$ nozzle diameter, and $5 \%$ infill density. In another study, Yadav, et al. [44] studied infill patterns and realized maximum compressive strength for the Hilbert pattern with the value of $121.35 \mathrm{MPa}$. Average SR values were the lowest, at $1.14 \mu \mathrm{m}$ and $1.895 \mu \mathrm{m}$ for $20 \%$ and $80 \%$ densities for rectilinear pattern, respectively. Lalegani Dezaki and Mohd Ariffin [45] proposed a novel method to combine solid, honeycomb, wiggle, grid, and rectilinear patterns in one dog-bone PLA sample to analyze their effects on tensile strength with different build orientations. In another study, the optimal condition was conducted in a sample with $0.5 \mathrm{~mm}$ layer thickness, $80 \%$ infill density and $65^{\circ}$ raster angle by developing a mathematical model [46]. Gopsill, et al. [47] optimized honeycomb infill pattern in beam-shaped products by various FEA scenarios to achieve the strongest design and density. Moreover, Heidari-Rarani, et al. [48] showed that $80 \%$ infill density, $0.1 \mathrm{~mm}$ layer thickness and $40 \mathrm{~mm} / \mathrm{s}$ printing speed were the appropriate conditions to achieve the best modulus of elasticity and ultimate tensile strength.

While FDM 3D printers are capable of generating infill patterns with different densities, designing patterns using CAD software packages has not been investigated yet. The main aim of this study is to address this research question and make a comparison between infill patterns with various densities generated by CAD and FDM printer in dog-bone shape PLA parts. Besides, FEA is used to understand the behavior of interlayers under tensile strength and find out the differences between printed and simulated CAD samples. The effects of generated patterns by CAD on SR and mechanical properties were examined. Then, CAD patterns were compared to the printed specimens by the FDM machine. Four patterns with different percentages of infill density were chosen due to their capabilities in being strong under different loads. The strength and SR analysis of these two batches were examined to find out the differences.

\section{Materials and Methods}

FDM parameters and their effects on the strength and surface texture have been examined in previous research [49-51]. In this case, infill pattern and density were the main goals showing how they influence dimensional accuracy, material usage, and mechanical properties. A broad range of patterns such as grid, honeycomb, wiggle, zigzag, and other shapes have been generated and produced by FDM printers, but not many research works have investigated designing patterns using the CAD process. Therefore, in this work, SR analysis and tensile strength were performed to analyze the effects of these two pattern batches in dog-bone samples. This sample was designed by following ISO/ASTM D638, the standard test method for tensile properties of plastics. As shown in Figure 2, the base structure was designed in CATIA V $5{ }^{\circledR}$ (Dassault Systèmes, Vélizy-Villacoublay, France), and regarded as tensile strength standards Type 1.
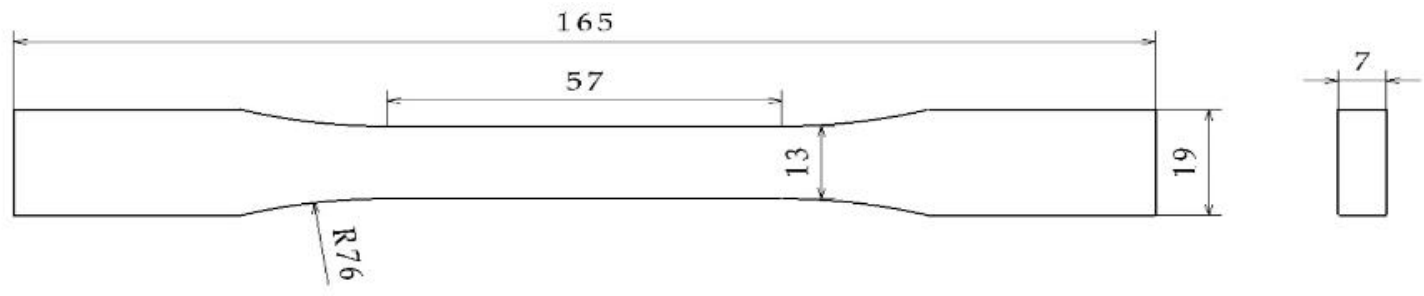

Figure 2. Drawing of a dog-bone shape sample. 
Concentric, grid, triangle, and zigzag patterns were chosen and designed as shown in Figure 3. A solid sample was also designed for the FDM process that slicer software followed the same pattern and density as the CAD procedure. Infill density was also another factor that was required to be analyzed. Therefore, each pattern was $3 \mathrm{D}$ printed with the same and different densities to investigate their effects for both groups (see Table 1). Based on the previous research by Lalegani Dezaki and Mohd Ariffin [45], the line width was set to $0.5 \mathrm{~mm}$ instead of $0.4 \mathrm{~mm}$ to avoid erroneous openings in the printed lines. The shell thickness was $0.8 \mathrm{~mm}$ for all samples. In the design procedure, patterns must be designed properly to avoid gaps and poor layer adhesion.
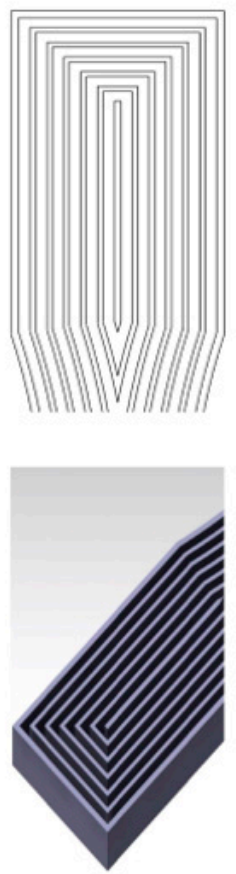

(a)
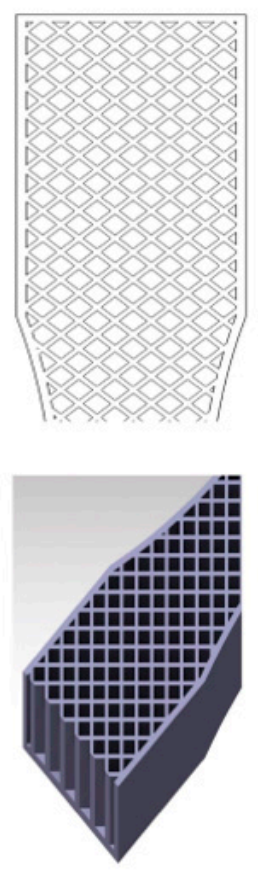

(b)
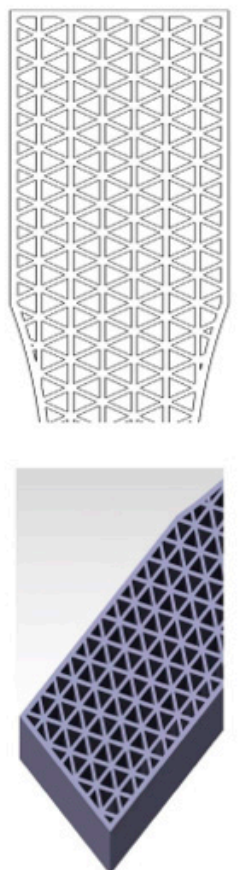

(c)
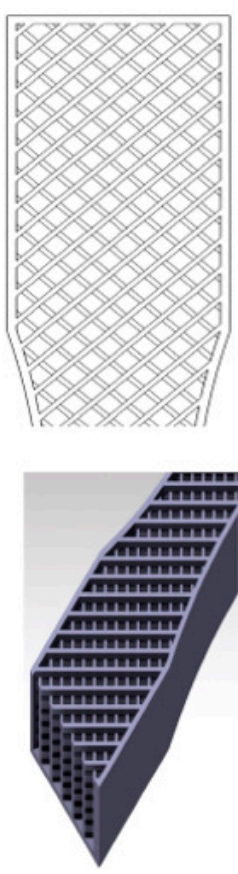

(d)

Figure 3. 2D/3D design of (a) concentric, (b) grid, (c) triangle and (d) zigzag patterns of sliced dog-bone samples.

Table 1. Infill density in CAD and FDM.

\begin{tabular}{|c|c|c|c|c|c|}
\hline Process & Infill Pattern & Infill Density (\%) & Process & Infill Pattern & Infill Density (\%) \\
\hline \multirow{4}{*}{ CAD } & Concentric & $\begin{array}{l}20 \\
30\end{array}$ & \multirow{4}{*}{ FDM } & Concentric & $\begin{array}{l}20 \\
30\end{array}$ \\
\hline & Grid & $\begin{array}{l}30 \\
60\end{array}$ & & Grid & $\begin{array}{l}30 \\
60\end{array}$ \\
\hline & Triangle & $\begin{array}{l}10 \\
40\end{array}$ & & Triangle & $\begin{array}{l}10 \\
40\end{array}$ \\
\hline & Zigzag & $\begin{array}{l}30 \\
50\end{array}$ & & Zigzag & $\begin{array}{l}30 \\
50\end{array}$ \\
\hline
\end{tabular}

Due to the high capability of FEA, it is possible to examine parts' behavior under compression or tensile tests [52]. Infill patterns indicate specific behavior in printed samples under different loads. Hence, analyzing samples is vital for finding the layer's reaction under tensile load. CAD samples were examined via Abaqus ${ }^{\circledR}$ (2020 version, Dassault Systèmes, Vélizy-Villacoublay, France) due to the existence of infill patterns before the printing process. The designed samples were converted to initial graphics specification 
(IGS) format in CATIA V5. Failures and von Mises in the simulation process were obtained. The method elaborated to find out the differences between printed and simulated CAD specimens. Static analysis, millimeter $(\mathrm{mm})$ unit, and PLA material properties were assigned in the simulation procedure. The type of mesh used in this process was quadratic tetrahedral elements of type C3D10. Features of each simulated CAD sample are provided in Table 2.

Table 2. Specimens' features in FEA process.

\begin{tabular}{|c|c|c|c|c|c|c|c|c|}
\hline \multirow{2}{*}{$\begin{array}{c}\text { CAD Sample } \\
\text { Infill density (\%) }\end{array}$} & \multicolumn{2}{|c|}{ Concentric } & \multicolumn{2}{|c|}{ Grid } & \multicolumn{2}{|c|}{ Triangle } & \multicolumn{2}{|c|}{ Zigzag } \\
\hline & 20 & 30 & 30 & 60 & 10 & 40 & 30 & 60 \\
\hline Mesh size & 3 & 3 & 3 & 3 & 3 & 3 & 3 & 3 \\
\hline Force $(\mathrm{N})$ & 2500 & 2500 & 2500 & 2500 & 2500 & 2500 & 2500 & 2500 \\
\hline No. of nodes & 30,851 & 42,627 & 61,543 & 147,310 & 29,122 & 53,964 & 27,532 & 48,223 \\
\hline No. of elements & 17,685 & 23,916 & 37,980 & 94,266 & 15,335 & 34,206 & 13,941 & 25,632 \\
\hline $\begin{array}{l}\text { Boundary } \\
\text { condition }\end{array}$ & & Di & ement & Gas & ngth & & astre typ & \\
\hline
\end{tabular}

3D mesh design

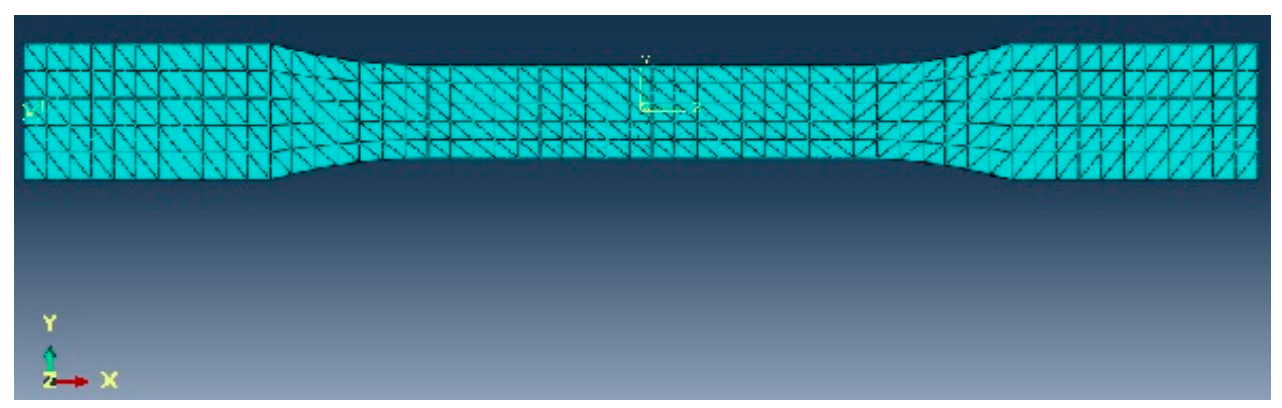

Ultimaker 3 Extended machine (Ultimaker, Geldermalsen, Netherlands) with two extruders was used to print all specimens. The biodegradable green PolyLite ${ }^{\mathrm{TM}}$ PLA material (Polymaker, Shanghai, China) with a $1.75 \mathrm{~mm}$ filament diameter was chosen due to its reliable properties, good strength, and stiffness (see Table 3) [53]. Due to the influences of build orientation on mechanical properties and SR in the FDM process, the $0^{\circ}$ angle which was printed on XY direction was picked because of its well-known effects with regard to less material consumption, good mechanical strength, and SR [34,54,55]. Preparing the STL file was done by Cura ${ }^{\circledR}$ (4.5 version, Ultimaker, Geldermalsen, Netherlands) to reach suitable G-codes. All parameters were constant for CAD and FDM specimens as shown in Table 4 . A total of 16 dog-bone samples (each pattern was printed once) were 3D-printed as shown in Figure 4. 
Table 3. PLA properties.

\begin{tabular}{cc}
\hline PLA Properties & Value \\
\hline Density $\left(\mathrm{g} / \mathrm{cm}^{3}\right)$ & 1.17 \\
Printing temperature $\left({ }^{\circ} \mathrm{C}\right)$ & $190-230$ \\
Printing speed $(\mathrm{mm} / \mathrm{s})$ & $40-60$ \\
Bed temperature $\left({ }^{\circ} \mathrm{C}\right)$ & $25-60$ \\
Tensile strength $(\mathrm{MPa})$ & $46.6 \pm 0.9$ \\
Young's Modulus $(\mathrm{MPa})$ & $2636 \pm 330$ \\
\hline
\end{tabular}

Table 4. Printing parameters for CAD and FDM specimens.

\begin{tabular}{cccccccccc}
\hline Process & $\begin{array}{c}\text { Build } \\
\text { Orientation } \\
(\text { Degree) }\end{array}$ & $\begin{array}{c}\text { Nozzle } \\
\text { Diameter } \\
(\mathbf{m m})\end{array}$ & $\begin{array}{c}\text { Filament } \\
\text { Diameter } \\
(\mathbf{m m})\end{array}$ & $\begin{array}{c}\text { Layer } \\
\text { Height } \\
(\mathbf{m m})\end{array}$ & $\begin{array}{c}\text { Nozzle } \\
\text { Temp. } \\
\left({ }^{\circ} \mathbf{C}\right)\end{array}$ & $\begin{array}{c}\text { Bed } \\
\text { Temp. } \\
\left({ }^{\circ} \mathbf{C}\right)\end{array}$ & $\begin{array}{c}\text { Print } \\
\text { Speed } \\
(\mathbf{m m} / \mathbf{s})\end{array}$ & $\begin{array}{c}\text { Wall } \\
\text { Thickness } \\
(\mathbf{m m})\end{array}$ & $\begin{array}{c}\text { Number } \\
\text { of } \\
\text { Top/Bottom Layer }\end{array}$ \\
\hline CAD & 0 & 0.4 & 1.75 & 0.15 & 200 & 60 & 80 & 1 & 7 \\
FDM & 0 & 0.4 & 1.75 & 0.15 & 200 & 60 & 80 & 1 & 7 \\
\hline
\end{tabular}

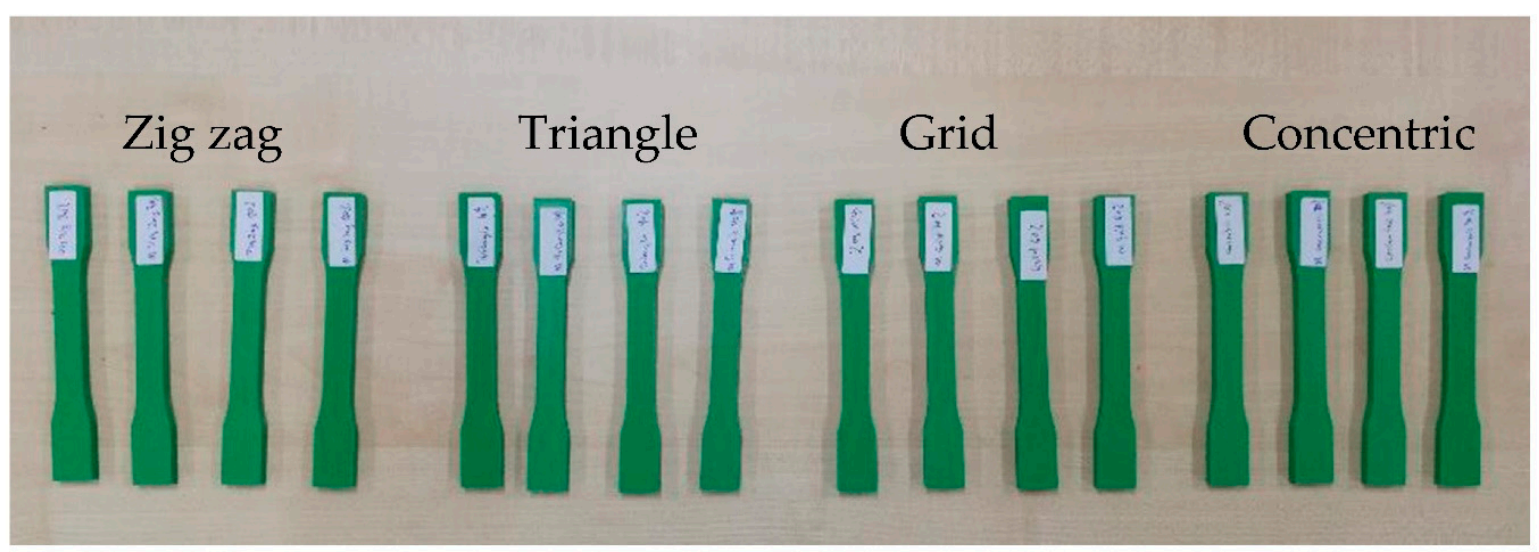

Figure 4. 3D-printed specimens based on CAD and FDM methods.

SR measurement was conducted to find out how surface quality varies based on patterns generated by CAD and FDM. The value of $R_{a}$ was recorded by the Mahr Perthometer S2 machine (Mahr Inc, Göttingen, Germany). Various factors affect surface quality such as waviness, peaks, and valleys. Hence, five points were chosen on the top side to analyze patterns' effects on surface texture in both procedures (see Figure 5). Tracing length with the value of $5.6 \mathrm{~mm}, 4.0 \mathrm{~mm}$ evaluation length, and $0.8 \mathrm{~mm}$ cut-off wavelength were chosen to achieve high accuracy and precision [56]. Meanwhile, to analyze the strength and stiffness of the specimens, vertical INSTRON 3365 (Instron, Norwood, MA, USA) with $5 \mathrm{kN}$ capacity and $1000 \mathrm{~mm} / \mathrm{min}$ maximum speed was employed. Displacements and cracks were recorded for each sample to analyze dissimilarities. Controlled speed via software for the upper jaw was $5 \mathrm{~mm} / \mathrm{min}$ at room temperature to achieve maximum strength. A microscopic view of selected specimens to see the pattern binding and structure was done by Leica MS5 (Leica Microsystems Inc., Buffalo Grove, IL, USA) with a five-step magnification changer up to 320x. The magnification of $10 x$ was chosen to examine the inside structure of patterns.

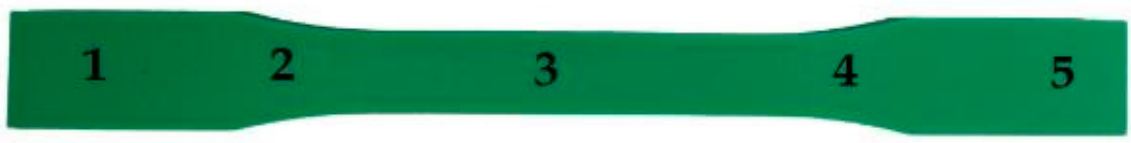

Figure 5. Points from top surface for SR measurement. 


\section{Results and Discussion}

\subsection{Effects of Infill Patterns on $S R$}

Weight measurement was conducted by Cura ${ }^{\circledR}$ software to examine differences between all samples. As shown in Table 5, the weight differences for patterns with the same density were $\pm 1 \mathrm{~g}$ accordingly. Designing the patterns to have better adhesion and avoid gaps was the vital section of this research. Thus, patterns were modeled to be close to patterns generated by the FDM 3D printer. Surface measurement was accomplished for all samples whereas before that the issues of surface and layer binding were examined to determine the effects of these two methods. All specimens' quality represented purity and clearness, however, defects were visible in the bottom layer in concentric samples generated by CAD. Figure 6 shows the issue in these two samples. The binding between layers was good but the initial layer (bottom layer) which was attached to the printing bed was not perfect, and the printed line was not attached properly. This issue was caused due to the poor temperature at the beginning of the process that led to weak bonding between some parts of the bottom layers.

Table 5. Weight differences for CAD and FDM samples.

\begin{tabular}{ccccc}
\hline $\begin{array}{c}\text { Process \& } \\
\text { Pattern }\end{array}$ & $\begin{array}{c}\text { Concentric } \mathbf{2 0} \% \\
\text { Concentric } \mathbf{3 0 \%}\end{array}$ & $\begin{array}{c}\text { Grid 30\% } \\
\text { Grid } \mathbf{6 0 \%}\end{array}$ & $\begin{array}{c}\text { Triangle 10\% } \\
\text { Triangle } \mathbf{4 0} \%\end{array}$ & $\begin{array}{c}\text { Zigzag 30\% } \\
\text { Zigzag 50\% }\end{array}$ \\
\hline \multirow{2}{*}{ CAD weight (gr) } & 12 & 15 & 10 & 12 \\
& 15 & 18 & 15 & 17 \\
FDM weight (gr) & 12 & 14 & 12 & 14 \\
& 14 & 18 & 16 & 17 \\
\hline
\end{tabular}
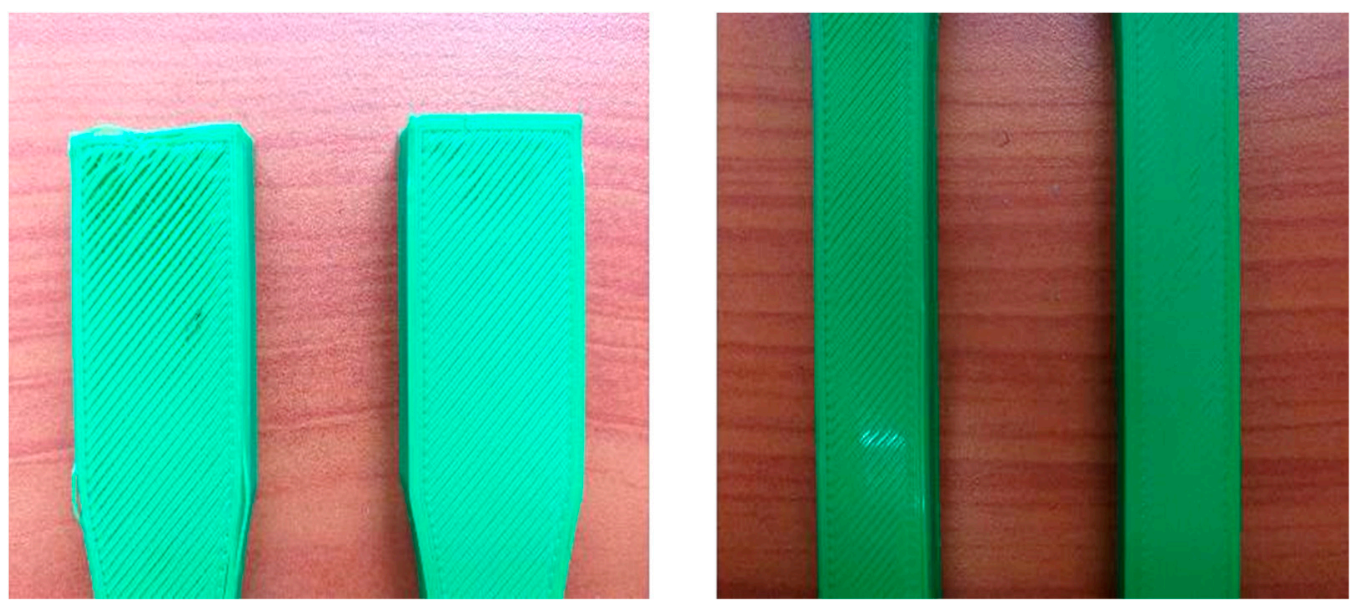

Figure 6. Issues in concentric CAD specimens in bottom layer.

Table 6 illustrates the average SR for each sample. Surprisingly, the quality of patterns generated by CAD was slightly better than those generated by the FDM machine. However, for zigzag pattern samples, the value of average $\mathrm{R}_{a}$ for generated FDM $(2.94 \mu \mathrm{m}$ for $30 \%$ infill density and $3.45 \mu \mathrm{m}$ for $50 \%$ ) was lower than CAD samples. This might cause the non-optimum design in pattern layers. In contrast, CAD samples showed better average $\mathrm{R}_{\mathrm{a}}$, and the surface texture was slightly superior compared to FDM parts. These results showed infill pattern and infill density affected texture and surface integrity. Meanwhile, the differences between CAD specimens are visible in Figures 7 and 8. The graphs were created in MATLAB ${ }^{\circledR}$ to clearly show the range of average waviness values (from $2 \mu \mathrm{m}$ to $7 \mu \mathrm{m}$ ). As shown in Figure 8, the zigzag samples have the worst surface quality among samples while grid and concentric samples have the best surface texture in the CAD procedure. This poor quality in the triangle sample was due to the design and classified layers. On the other hand, Figure 7 shows the quality of each point for patterns generated 
by FDM machine. As can be seen, triangle patterns resulted in poor surface texture among other samples. This means that the value of $R_{a}$ for each point was higher. The grid sample showed the best quality and the lowest average value among FDM printed samples, with $2.85 \mu \mathrm{m}$ and $2.67 \mu \mathrm{m}$ for $30 \%$ and $60 \%$, respectively. The differences in SR were examined and results showed patterns generated by CAD parts were slightly better compared to the FDM machine. Also, grid samples had the best surface integrity compared to other specimens. The surface texture was almost the same and the value of average waviness in all specimens fluctuated in the same range.

Table 6. The average SR of printed samples.

\begin{tabular}{|c|c|c|c|c|c|c|c|c|}
\hline \multirow{2}{*}{ Point } & \multicolumn{4}{|c|}{ Grid Pattern } & \multicolumn{4}{|c|}{ Zigzag Pattern } \\
\hline & Part & $\mathbf{R}_{\mathrm{a}}(\mu \mathrm{m})$ & Part & $\mathbf{R}_{\mathbf{a}}(\mu \mathrm{m})$ & Part & $\mathbf{R}_{\mathrm{a}}(\mu \mathrm{m})$ & Part & $\mathbf{R}_{\mathrm{a}}(\mu \mathrm{m})$ \\
\hline 1 & \multirow{7}{*}{$\begin{array}{l}\text { CAD } \\
30 \%\end{array}$} & 2.37 & & 2.54 & \multirow{7}{*}{$\begin{array}{l}\text { CAD } \\
30 \%\end{array}$} & 6.78 & \multirow{7}{*}{$\begin{array}{c}\text { FDM } \\
30 \%\end{array}$} & 2.78 \\
\hline 2 & & 2.17 & & 2.77 & & 5.6 & & 3.3 \\
\hline 3 & & 2.45 & FDM & 2.93 & & 6.11 & & 3.4 \\
\hline 4 & & 3.49 & $30 \%$ & 3.14 & & 5.63 & & 2.93 \\
\hline 5 & & 3.1 & & 2.89 & & 7.3 & & 2.27 \\
\hline Average & & 2.72 & & 2.85 & & 6.28 & & 2.94 \\
\hline $\begin{array}{l}\text { Standard } \\
\text { deviation }\end{array}$ & & 0.56 & & 0.22 & & 0.74 & & 0.45 \\
\hline 1 & \multirow{7}{*}{$\begin{array}{c}\text { CAD } \\
60 \%\end{array}$} & 2.52 & & 3.07 & \multirow{7}{*}{$\begin{array}{c}\text { CAD } \\
50 \%\end{array}$} & 4.83 & & 3.73 \\
\hline 2 & & 2.19 & & 3.57 & & 4.88 & & 3.81 \\
\hline 3 & & 2.25 & FDM & 2.42 & & 4.5 & FDM & 2.94 \\
\hline 4 & & 2.78 & $60 \%$ & 2.02 & & 4.7 & $50 \%$ & 3.47 \\
\hline 5 & & 2.54 & & 2.3 & & 4.3 & & 3.26 \\
\hline Average & & 2.45 & & 2.67 & & 4.64 & & 3.45 \\
\hline \multirow[t]{2}{*}{$\begin{array}{l}\text { Standard } \\
\text { deviation }\end{array}$} & & 0.24 & & 0.63 & & 0.24 & & 0.36 \\
\hline & \multicolumn{4}{|c|}{ Concentric pattern } & \multicolumn{4}{|c|}{ Triangle pattern } \\
\hline 1 & \multirow{7}{*}{$\begin{array}{l}\text { CAD } \\
20 \%\end{array}$} & 2.12 & & 3.11 & \multirow{7}{*}{$\begin{array}{l}\text { CAD } \\
10 \%\end{array}$} & 3.47 & \multirow{7}{*}{$\begin{array}{c}\text { FDM } \\
10 \%\end{array}$} & 3.12 \\
\hline 2 & & 2.86 & & 3.33 & & 2.64 & & 3.7 \\
\hline 3 & & 2.4 & FDM & 3.25 & & 3.78 & & 4.17 \\
\hline 4 & & 2.78 & $20 \%$ & 3.61 & & 3.4 & & 4.96 \\
\hline 5 & & 2.62 & & 3.17 & & 2.77 & & 3.81 \\
\hline Average & & 2.55 & & 3.29 & & 3.21 & & 3.95 \\
\hline $\begin{array}{l}\text { Standard } \\
\text { deviation }\end{array}$ & & 0.30 & & 0.20 & & 0.49 & & 0.68 \\
\hline 1 & \multirow{7}{*}{$\begin{array}{l}\text { CAD } \\
30 \%\end{array}$} & 1.97 & & 3.08 & \multirow{7}{*}{$\begin{array}{c}\text { CAD } \\
40 \%\end{array}$} & 2.83 & \multirow{7}{*}{$\begin{array}{c}\text { FDM } \\
40 \%\end{array}$} & 3.11 \\
\hline 2 & & 2.23 & & 3.89 & & 3.03 & & 3.85 \\
\hline 3 & & 2.38 & FDM & 2.74 & & 3.13 & & 4.41 \\
\hline 4 & & 2.56 & $30 \%$ & 3.47 & & 2.87 & & 3.9 \\
\hline 5 & & 2.77 & & 2.22 & & 3.04 & & 2.82 \\
\hline Average & & 2.38 & & 3.08 & & 2.98 & & 3.62 \\
\hline $\begin{array}{l}\text { Standard } \\
\text { deviation }\end{array}$ & & 0.31 & & 0.64 & & 0.13 & & 0.64 \\
\hline
\end{tabular}




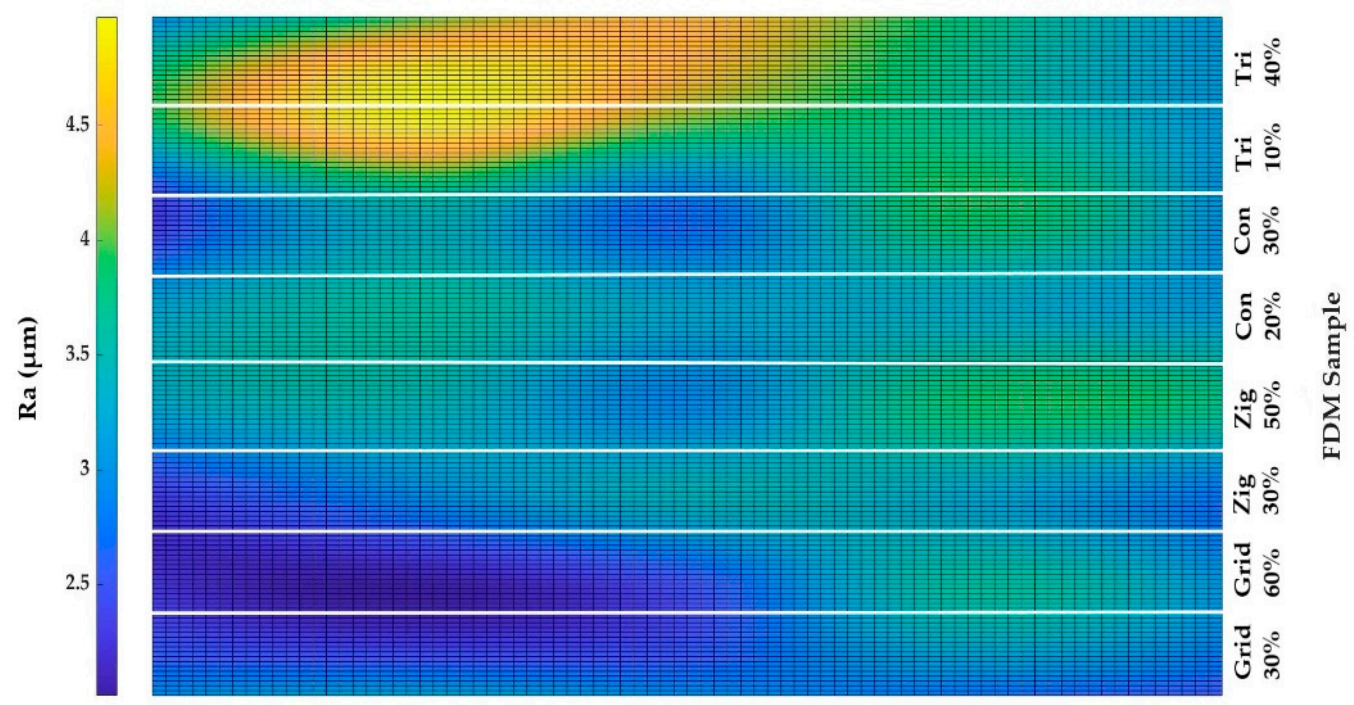

Top Surface

Figure 7. 2D graph of SR measurements in FDM parts.

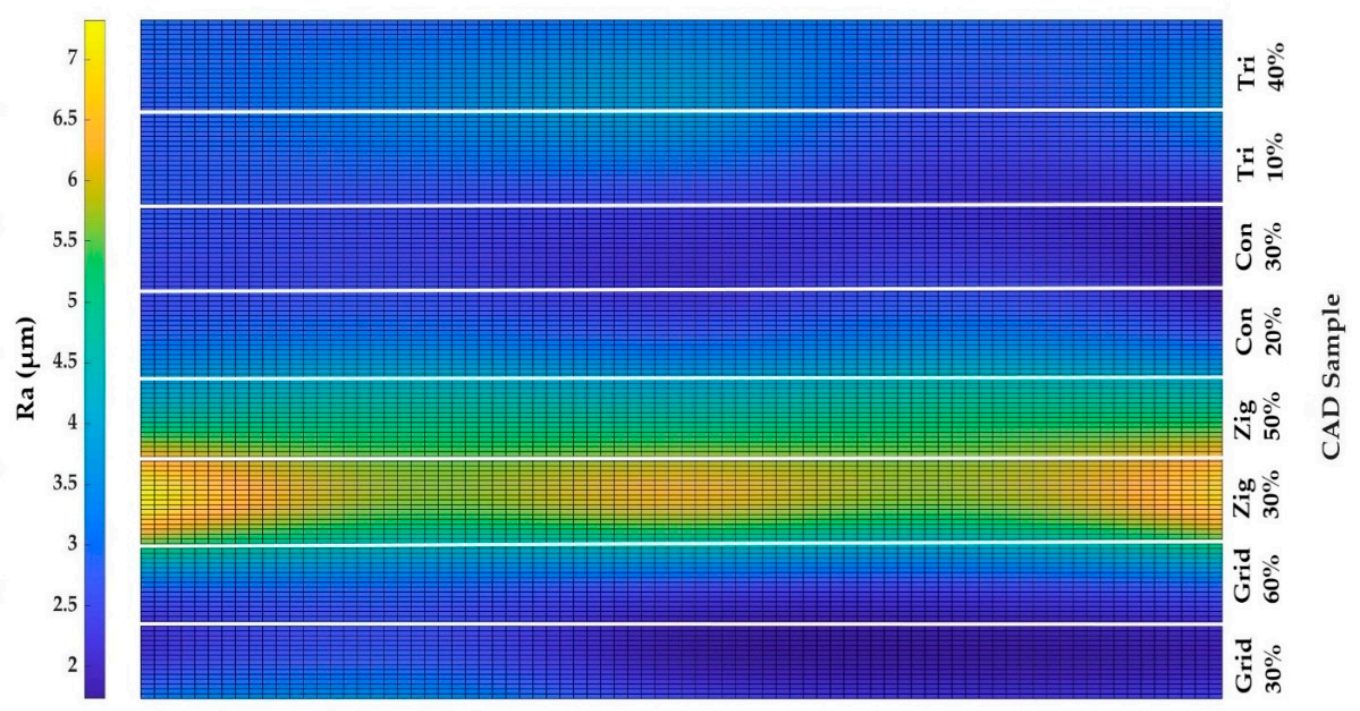

Top Surface

Figure 8. 2D graph of SR measurements in CAD parts.

\subsection{Effects of Infill Patterns on Mechanical Properties}

This research is conducted to analyse the behaviour of infill patterns, various densities, and layer bonding in dog-bone samples via CAD and FDM processes. Failures in each printed specimen were recorded in both simulation and experiment procedures. Internal structure and defects were examined properly to investigate material properties. The main goal of FEA was to determine the patterns' reactions under the tensile test. Sometimes, slicing softwares are not able to generate specific patterns in printed products. Hence, modifying personalized infill patterns with high strength and stiffness can be achieved by CAD design. The von Mises and stresses were examined with the same condition under mentioned loads. Analysing stress-strain of CAD parts was done by choosing one element in the middle of dog-bone samples. The maximum von Mises of 4 CAD samples is recorded in Table 7 to compare each infill pattern and find out the weakest and strongest under the tensile test. 
Table 7. von Mises in CAD samples.

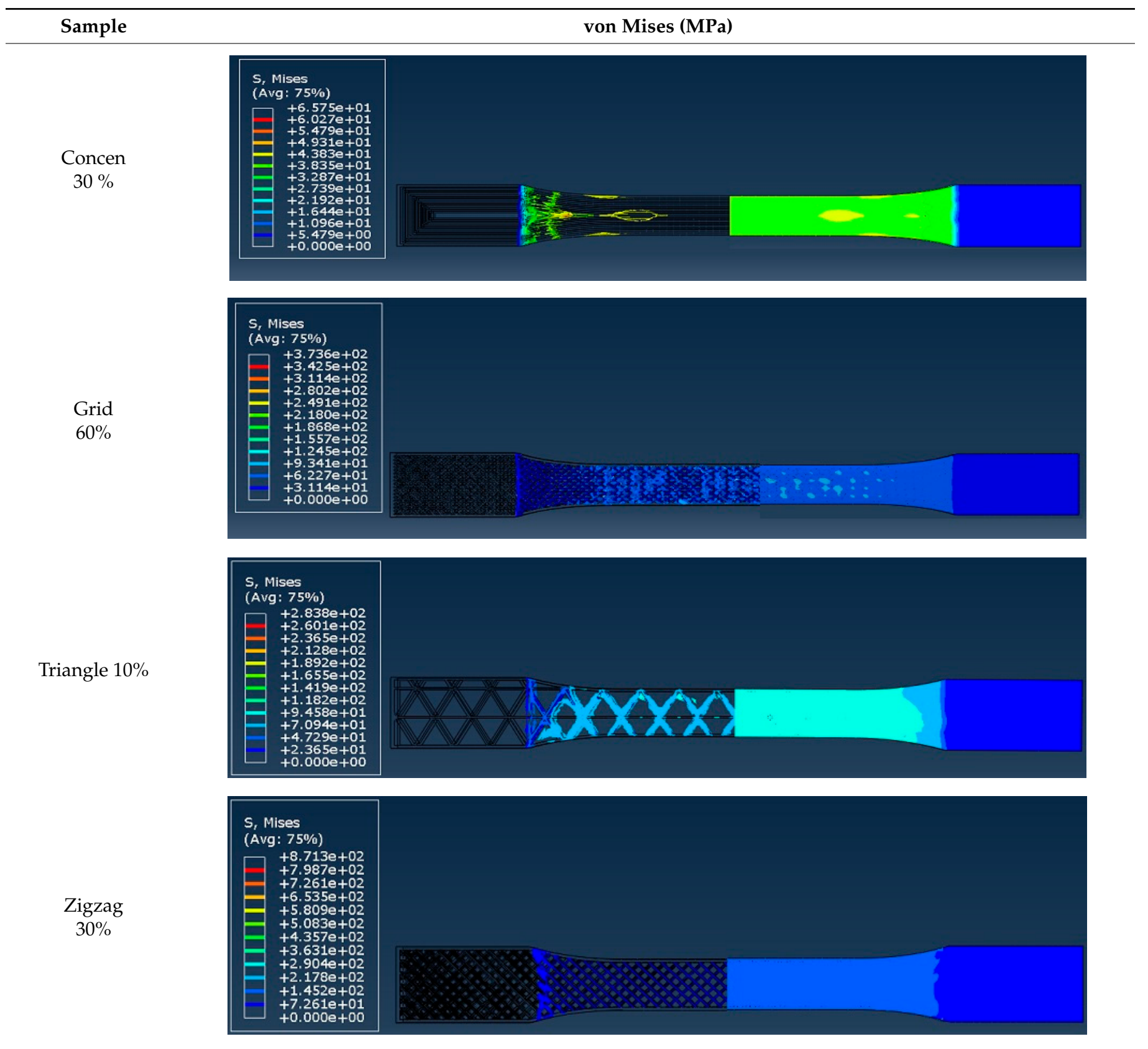

As shown in Table 7, cracks and failures happened in interlayer bonding between each layer inside the samples. Initially, internal patterns inside the samples started to crack, followed by a failure in the area of the gauge length. Concentric and grid specimens were the strongest samples, among others, under $2500 \mathrm{~N}$ force. This means weight can be minimized by choosing an appropriate infill pattern without sacrificing strength. However, increasing density in printed samples led to heavier and stronger products. It can be seen that grid and concentric samples are the strongest while the zigzag and triangle with 10\% density samples are the weakest. It is also shown how infill density can affect products' strength and stiffness. In spite of infill density effects, concentric samples have almost corresponding strength. In brief, the grid sample with $60 \%$ infill density was the strongest, followed by the concentric sample with $30 \%$ density.

Figure 9 shows failure (load-extension) for each pattern with different densities in the printing process. A wide range of loads was applied to crack grid, concentric, triangle, and 
zigzag patterns in dog-bone samples. Figure $9 \mathrm{~b}$ shows that concentric FDM specimens are strongest, among other parts. Each sample cracked at a specific load which meant pattern and density were effective in their mechanical properties. A concentric pattern with $30 \%$ infill density generated by the FDM printer was the strongest sample with $2731.65 \mathrm{~N}$ maximum tensile load, which was close to that of the FEA process. The maximum stress at this load was $30.02 \mathrm{MPa}$. In contrast, the zigzag pattern with $30 \%$ density generated by CAD was the weakest part with $1264.45 \mathrm{~N}$, among other 3D printed samples. Almost every sample cracked around $2 \mathrm{~mm}$ extension, while a few parts were displaced more because the infill patterns inside the parts stuck together. That was the reason to examine the internal structure to achieve a reliable result and determine the differences with FEA.

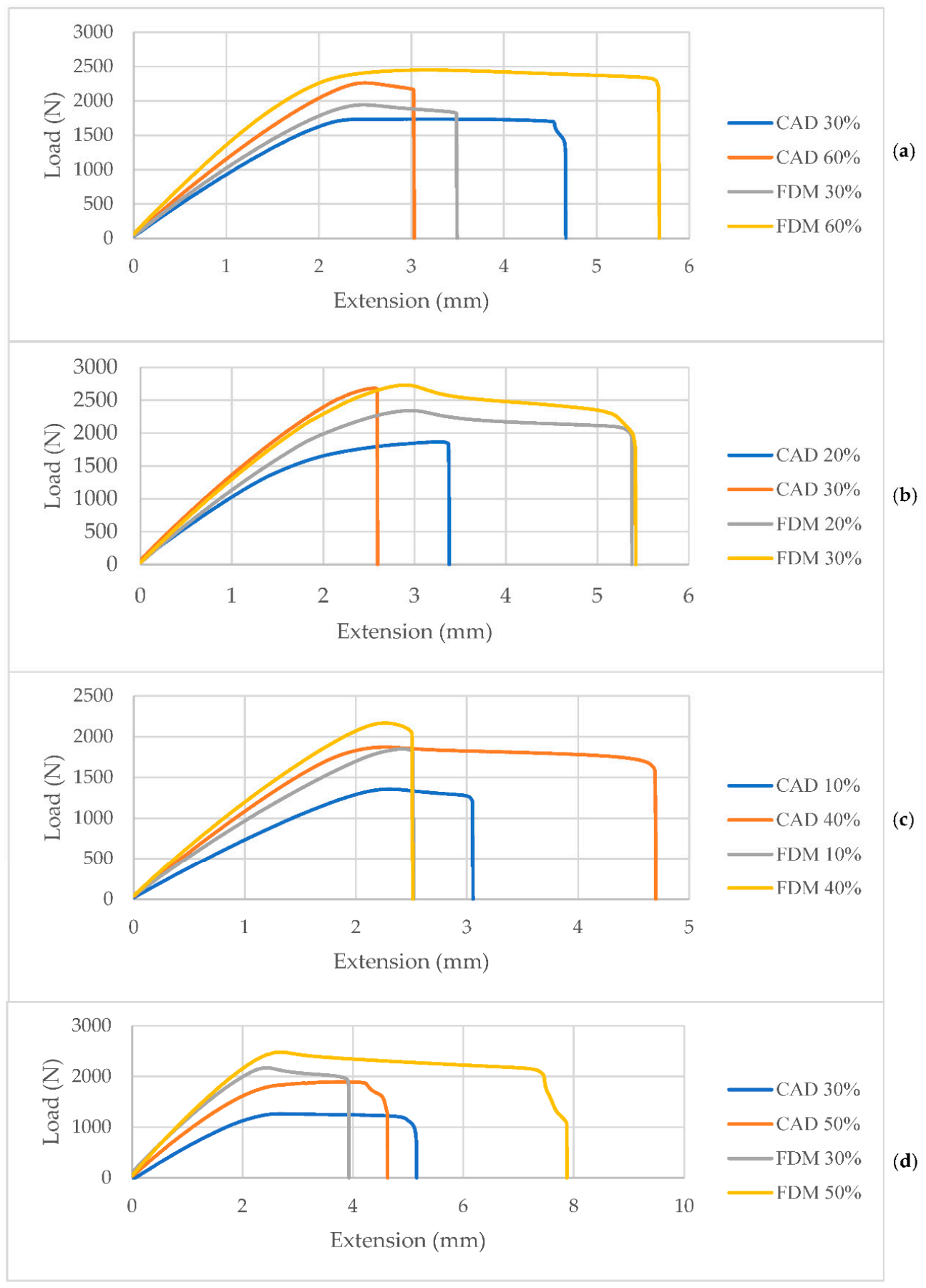

Figure 9. Failure graphs of (a) grid, (b) concentric, (c) triangle, and (d) zigzag patterns for CAD and FDM parts in the experiment. 
A comparison between all samples was conducted to show at what load specimens started to crack. Figure 10 indicates concentric samples in both FDM and CAD had better strength while the density was lower. The following strong pattern was a grid with different densities, the same as the FEA procedure. Further, in triangle patterns, the FDM part with $10 \%$ density was almost as good as the CAD sample with $40 \%$ density. In contrast, as shown in Table 8, the weakest CAD samples were for the zigzag pattern with $1264.45 \mathrm{~N}$ and $1893.47 \mathrm{~N}$ for $30 \%$ and $50 \%$ density, respectively. All specimens cracked at the gauge length area but the cracked lines in zigzag patterns generated by CAD were perpendicular (see Figure 11). The cracks started from failure of the internal structure and subsequently the bottom layers due to the poor binding that was mentioned before. The lower strength in CAD samples might happen due to the non-optimized design and poor binding of patterns in the internal structure. Subsequently, the top layer in samples cracked because of strong binding between line width. Hence, this issue was investigated in the form of a microscopic view inside the samples in the following section.

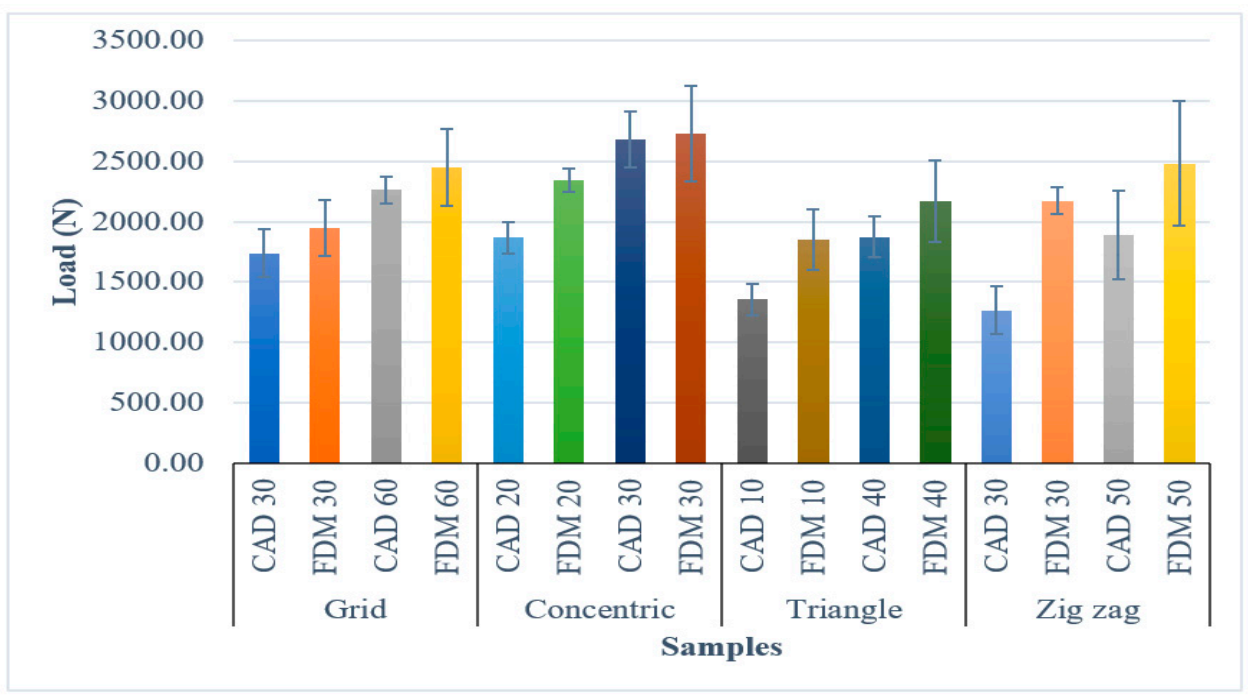

Figure 10. Maximum strength comparison in printed samples.

Table 8. Stress, strain, and maximum load in the tensile test.

\begin{tabular}{cccccc}
\hline Pattern & $\begin{array}{c}\text { Infill } \\
\text { Density (\%) }\end{array}$ & $\begin{array}{c}\text { Maximum } \\
\text { Load (N) }\end{array}$ & $\begin{array}{c}\text { Stress at } \\
\text { Max. Load } \\
\text { (MPa) }\end{array}$ & $\begin{array}{c}\text { Strain at } \\
\text { Max. Load } \\
\mathbf{( \% )}\end{array}$ & $\begin{array}{c}\text { Standard } \\
\text { Deviation }\end{array}$ \\
\hline \multirow{5}{*}{ Grid } & CAD 30 & 1736 & 19.08 & 6.65 & 198 \\
& FDM 30 & 1944 & 21.36 & 4.96 & 231 \\
& CAD 60 & 2263 & 24.87 & 4.99 & 110 \\
& FDM 60 & 2452 & 26.95 & 6.41 & 320 \\
\hline \multirow{5}{*}{ Concentric } & CAD 20 & 1866 & 20.51 & 6.57 & 131 \\
& FDM 20 & 2342 & 25.74 & 5.92 & 98 \\
& CAD 30 & 2683 & 29.49 & 5.13 & 230 \\
& FDM 30 & 2732 & 30.02 & 5.79 & 399 \\
\hline \multirow{5}{*}{ Triangle } & CAD 10 & 1357 & 14.92 & 4.57 & 130 \\
& FDM 10 & 1851 & 20.34 & 4.82 & 253 \\
& CAD 40 & 1873 & 20.58 & 4.55 & 167 \\
& FDM 40 & 2168 & 23.82 & 4.52 & 336 \\
\hline \multirow{5}{*}{ Zigzag } & CAD 30 & 1264 & 13.9 & 5.42 & 200 \\
& FDM 30 & 2172 & 23.87 & 4.88 & 111 \\
& CAD 50 & 1893 & 20.81 & 7.78 & 367 \\
& FDM 50 & 2481 & 27.27 & 5.37 & 518 \\
\hline
\end{tabular}




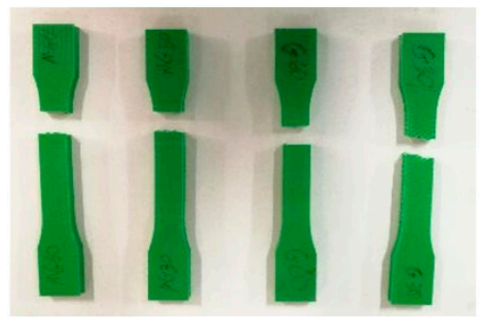

(a)

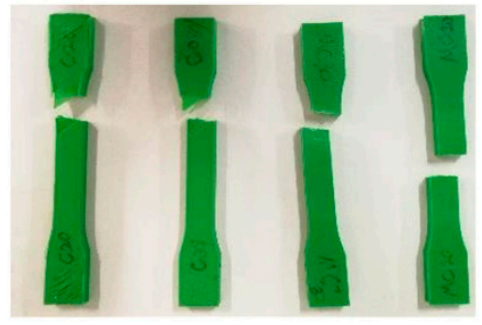

(c)

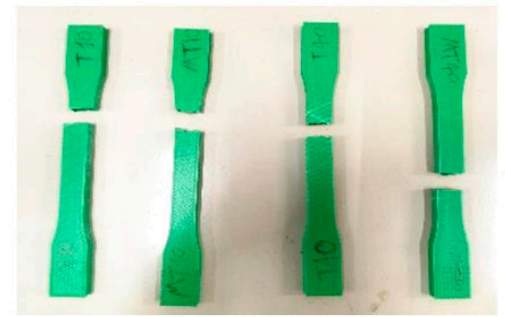

(b)

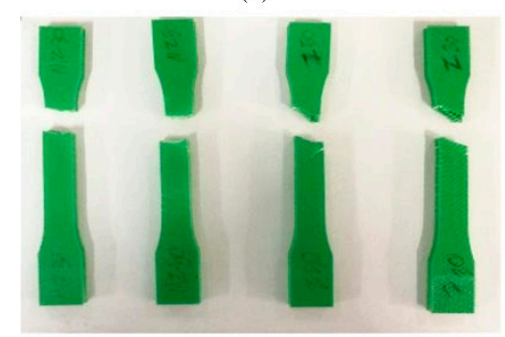

(d)

Figure 11. Failure areas in (a) grid, (b) triangle, (c) concentric, and (d) zigzag patterns of the printed parts.

Results showed that by increasing infill density, samples' strength increased as well. Lower density resulted in weaker parts but with lower weight. Undoubtedly, solid or $100 \%$ density is the strongest way to $3 \mathrm{D}$ print products but weight is maximum in the final sample. Different crack lines occurred due to the pattern structures and various binding behaviors. However, other elements are vital to enhance stiffness and strength, in this study, infill effects were examined for two different production methods. In brief, patterns that were generated by the FDM printer showed better strength and mechanical properties compared to the CAD specimens. This means adhesion between layers was a little bit weaker in CAD products. According to the infill structure, the microscopic view of printed patterns was analyzed to identify issues inside the specimens.

Concerning the mechanical properties and strength of the 3D-printed sample, infill structures were examined throughout the cracked areas. As shown in Figure 12, all CAD and FDM printed samples follow the same structure. Layer printing structures were totally visible inside the samples, which showed the reason why each part cracked at specific loads. The reason why the concentric pattern tolerated higher tensile load was the pattern generated in the same direction as the tensile load. The same thing happens in FEA procedure, and internal layers started to crack in both procedure due to poor binding. Apart from this, cracks occurred in internal layers in the FDM process due to poor binding. This drawback might cause weaker samples in the CAD procedure. Besides, defects in zigzag pattern generated by CAD with 50\% density are shown in Figure $12 \mathrm{~b}$. Gaps and voids were greater in the CAD process compared to the FDM printing procedure. This obstacle led to lighter and weaker final products. Also, layer adhesion in the internal structure was affected by this defect in CAD samples. 


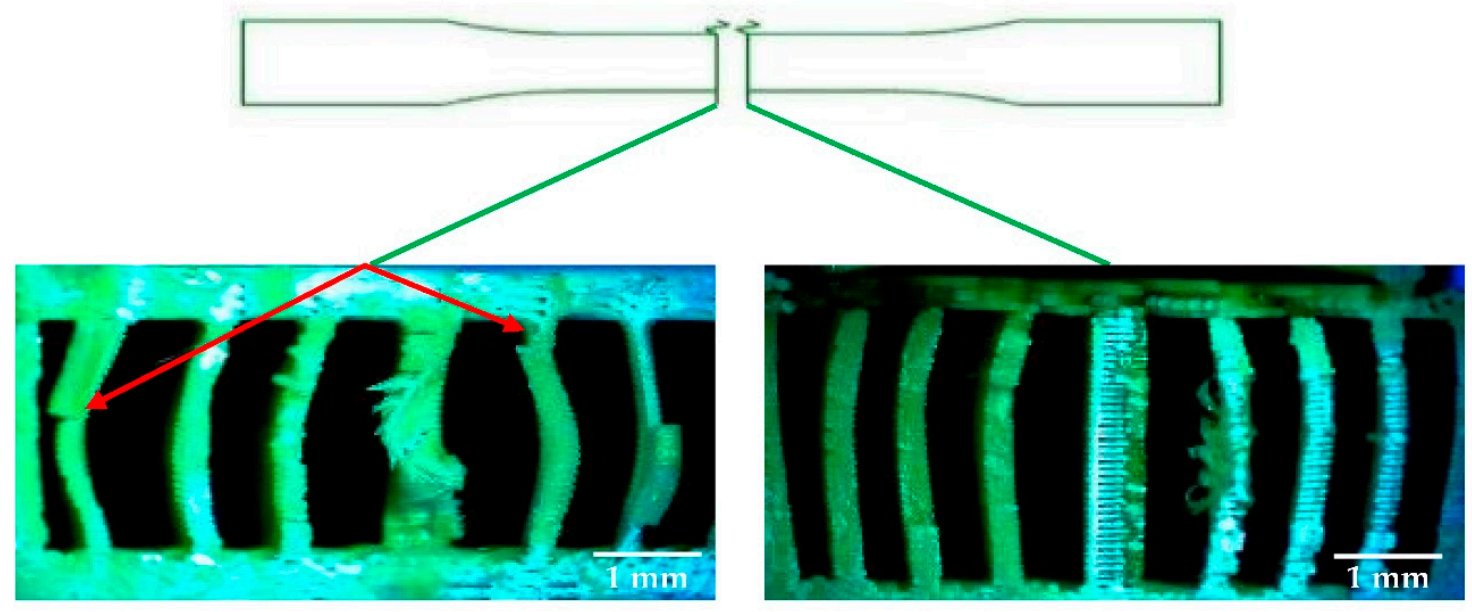

(a) Concentric pattern with $50 \%$ density
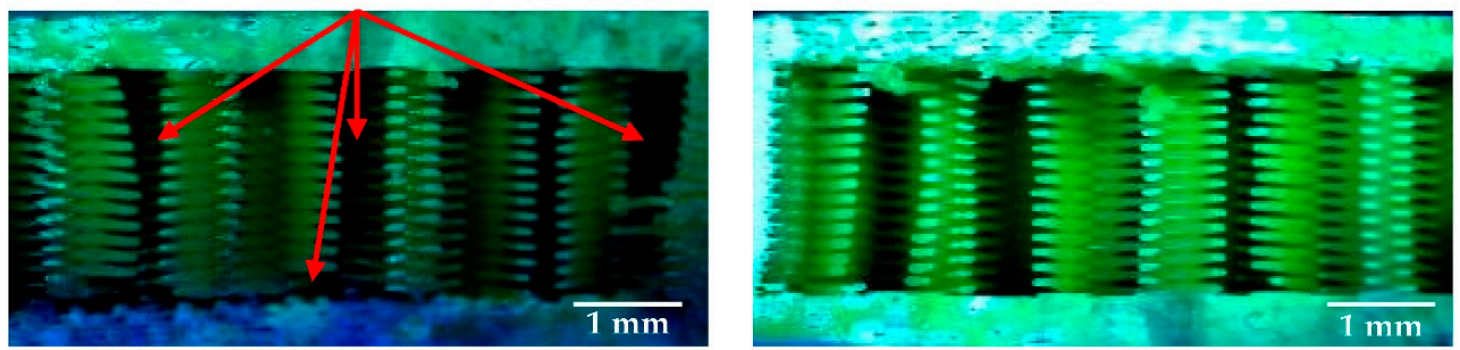

(b) Zigzag pattern with $50 \%$ density
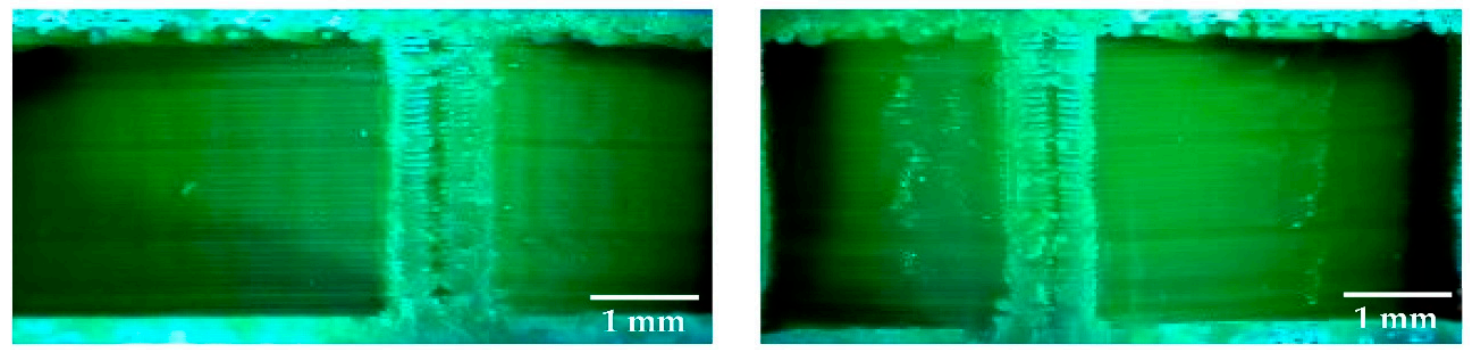

(c) Triangle pattern with $10 \%$ density
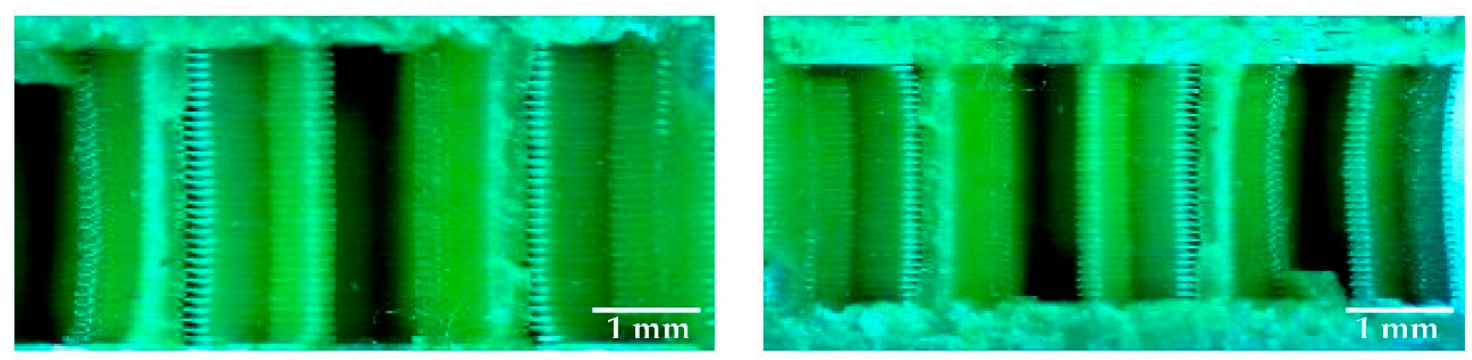

(d) Grid pattern with $60 \%$ density

Figure 12. Microscopic view of crack areas in (a) concentric, (b) zigzag, (c) triangle, and (d) grid patterns in CAD (left) and FDM (right) specimens.

In contrast, the triangle and grid patterns which are shown in Figure $12 \mathrm{c}, \mathrm{d}$ are neat and clear in both procedures. Finding an appropriate design and density was effective in both ways. This means layer classification is crucial in achieving the highest stiffness. 
If each layer sticks to the previous one properly, the strength of the printed part becomes better as well. This task can be done with optimum temperature and melting process. Poor layer adhesion affected surface quality and strength due to the rough and not aligned structure. Also, the attachment between internal patterns and wall thickness is important. The gaps between these two sections lead to poor mechanical properties and weak samples. Weight divergences were not excessive but density had a direct effect on weight. Further, SR was slightly better in CAD samples compared to the FDM, but samples generated by FDM were moderately stronger.

Both techniques were useful for building infill patterns. The differences between simulated and printed items were not excessive, and both procedures resulted the same strength and stiffness. As an example, FDM printers are not able to combine patterns in one sample. Hence, it is not possible to develop a product with various infill designs. In contrast, developing a highly complex pattern in a CAD system is difficult in some cases. Hence, by eliminating obstacles in both operations, producing highly complex patterns such as sandwich structures and bone scaffolds with maximum quality is achievable.

\section{Conclusions}

Infill pattern and infill density had direct effects on the surface quality and mechanical properties of 3D-printed products. Two techniques were used for producing PLA dog-bone samples. Four patterns, namely grid, triangle, zigzag, and concentric were picked and designed in a CAD system with different densities. These pattern structures followed the same structure as FDM machine-printed patterns in various conditions. Different densities were also chosen to examine their effects on surface quality and mechanical properties. FEA was used to examine the CAD samples under tensile load. Results indicated that CAD specimens were slightly better in terms of surface quality. Grid and concentric patterns had the best surface quality while the zigzag pattern was the worst due to its non-optimal design and poor adhesion. Moreover, the tensile strength test and microscopic analysis showed that a concentric pattern was the strongest in both the CAD and FDM techniques while zigzag pattern had the worst mechanical strength, among others. Future studies should be conducted on topology optimization of pattern design to reduce weight and increase strength.

Author Contributions: M.L.D. and M.B. collected research papers. M.L.D. deduced useful information from these papers under the supervision of A.S., A.Z., M.K.A.M.A. and M.B., M.L.D., S.H., and M.B. prepared a draft paper, and A.S., A.Z. and M.K.A.M.A. revised it from the perspectives of correctness, language, and information flow. All authors have read and agreed to the published version of the manuscript.

Funding: This research was funded by Universiti Putra Malaysia (UPM) [grant number 5540065].

Institutional Review Board Statement: Not applicable.

Informed Consent Statement: Not applicable.

Data Availability Statement: Not applicable.

Conflicts of Interest: The authors declare no conflict of interest.

\section{References}

1. Dezaki, M.L.; Ariffin, M.K.A.M.; Hatami, S. An overview of fused deposition modelling (FDM): Research, development and process optimisation. Rapid Prototyp. J. 2021, 27, 562-582. [CrossRef]

2. Askari, M.; Naniz, M.A.; Kouhi, M.; Saberi, A.; Zolfagharian, A.; Bodaghi, M. Recent progress in extrusion 3D bioprinting of hydrogel biomaterials for tissue regeneration: A comprehensive review with focus on advanced fabrication techniques. Biomater. Sci. 2021, 9, 535-573. [CrossRef] [PubMed]

3. Tosto, C.; Tirillò, J.; Sarasini, F.; Cicala, G. Hybrid Metal/Polymer Filaments for Fused Filament Fabrication (FFF) to Print Metal Parts. Appl. Sci. 2021, 11, 1444. [CrossRef]

4. Osswald, T.A.; Puentes, J.; Kattinger, J. Fused filament fabrication melting model. Addit. Manuf. 2018, 22, 51-59. [CrossRef]

5. Tlegenov, Y.; Hong, G.S.; Lu, W.F. Nozzle condition monitoring in 3D printing. Robot. Comput. Integr. Manuf. 2018, 54, 45-55. [CrossRef] 
6. Moretti, M.; Rossi, A.; Senin, N. In-process simulation of the extrusion to support optimisation and real-time monitoring in fused filament fabrication. Addit. Manuf. 2021, 38, 101817. [CrossRef]

7. Nieto, D.; Sánchez, D. Design for Additive Manufacturing: Tool Review and a Case Study. Appl. Sci. 2021, 11, 1571. [CrossRef]

8. Yu, H.; Hong, H.; Cao, S.; Ahmad, R. Topology Optimization for Multipatch Fused Deposition Modeling 3D Printing. Appl. Sci. 2020, 10, 943. [CrossRef]

9. Bourell, D.; Kruth, J.P.; Leu, M.; Levy, G.; Rosen, D.; Beese, A.; Clare, A. Materials for additive manufacturing. CIRP Ann. 2017, 66, 659-681. [CrossRef]

10. Cuiffo, M.A.; Snyder, J.; Elliott, A.M.; Romero, N.; Kannan, S.; Halada, G.P. Impact of the Fused Deposition (FDM) Printing Process on Polylactic Acid (PLA) Chemistry and Structure. Appl. Sci. 2017, 7, 579. [CrossRef]

11. Kaščak, J.; Gašpár, S.; Paško, J.; Knapčíková, L.; Husár, J.; Baron, P.; Török, J. Design of an Atypical Construction of Equipment for Additive Manufacturing with a Conceptual Solution of a Printhead Intended for the Use of Recycled Plastic Materials. Appl. Sci. 2021, 11, 2928. [CrossRef]

12. Liu, Z.; Wang, Y.; Wu, B.; Cui, C.; Guo, Y.; Yan, C. A critical review of fused deposition modeling 3D printing technology in manufacturing polylactic acid parts. Int. J. Adv. Manuf. Technol. 2019, 102, 2877-2889. [CrossRef]

13. Soltani, A.; Noroozi, R.; Bodaghi, M.; Zolfagharian, A.; Hedayati, R. 3D Printing On-Water Sports Boards with Bio-Inspired Core Designs. Polymers 2020, 12, 250. [CrossRef] [PubMed]

14. Kuo, C.-C.; Wu, Y.-R.; Li, M.-H.; Wu, H.-W. Minimizing warpage of ABS prototypes built with low-cost fused deposition modeling machine using developed closed-chamber and optimal process parameters. Int. J. Adv. Manuf. Technol. 2018, 101, 593-602. [CrossRef]

15. Huang, Q.; Zhang, J.; Sabbaghi, A.; Dasgupta, T. Optimal offline compensation of shape shrinkage for three-dimensional printing processes. IIE Trans. 2014, 47, 431-441. [CrossRef]

16. Chohan, J.S.; Singh, R.; Boparai, K.S. Mathematical modelling of surface roughness for vapour processing of ABS parts fabricated with fused deposition modelling. J. Manuf. Process. 2016, 24, 161-169. [CrossRef]

17. Bodaghi, M.; Damanpack, A.; Hu, G.; Liao, W. Large deformations of soft metamaterials fabricated by 3D printing. Mater. Des. 2017, 131, 81-91. [CrossRef]

18. Jiang, J.; Lou, J.; Hu, G. Effect of support on printed properties in fused deposition modelling processes. Virtual Phys. Prototyp. 2019, 14, 308-315. [CrossRef]

19. Bedi, P.; Singh, R.; Ahuja, I. Multifactor optimization of FDM process parameters for development of rapid tooling using $\mathrm{SiC} / \mathrm{Al} 2 \mathrm{O} 3-$ reinforced LDPE filament. J. Thermoplast. Compos. Mater. 2018, 33, 581-598. [CrossRef]

20. Moradi, M.; Moghadam, M.K.; Shamsborhan, M.; Bodaghi, M.; Falavandi, H. Post-Processing of FDM 3D-Printed Polylactic Acid Parts by Laser Beam Cutting. Polymers 2020, 12, 550. [CrossRef]

21. Barari, A.; Kishawy, H.A.; Kaji, F.; Elbestawi, M.A. On the surface quality of additive manufactured parts. Int. J. Adv. Manuf. Technol. 2016, 89, 1969-1974. [CrossRef]

22. Marwah, O.M.F.; Sharif, S.; Ibrahim, M.; Mohamad, E.J.; Idris, M.H. Direct rapid prototyping evaluation on multijet and fused deposition modeling patterns for investment casting. Proc. Inst. Mech. Eng. Part L J. Mater. Des. Appl. 2015, 230, 949-958. [CrossRef]

23. Solomon, I.J.; Sevvel, P.; Gunasekaran, J. A review on the various processing parameters in FDM. Mater. Today Proc. 2021, 37, 509-514. [CrossRef]

24. Vaezi, M.; Seitz, H.; Yang, S. A review on 3D micro-additive manufacturing technologies. Int. J. Adv. Manuf. Technol. 2013, 67, 1721-1754. [CrossRef]

25. Naveed, N. Investigate the effects of process parameters on material properties and microstructural changes of 3D-printed specimens using fused deposition modelling (FDM). Mater. Technol. 2020, 1-14. [CrossRef]

26. Ziemian, S.; Okwara, M.; Ziemian, C.W. Tensile and fatigue behavior of layered acrylonitrile butadiene styrene. Rapid Prototyp. J. 2015, 21, 270-278. [CrossRef]

27. Durgun, I.; Ertan, R. Experimental investigation of FDM process for improvement of mechanical properties and production cost. Rapid Prototyp. J. 2014, 20, 228-235. [CrossRef]

28. Yang, L.; Li, S.; Li, Y.; Yang, M.; Yuan, Q. Experimental Investigations for Optimizing the Extrusion Parameters on FDM PLA Printed Parts. J. Mater. Eng. Perform. 2018, 28, 169-182. [CrossRef]

29. Camposeco-Negrete, C. Optimization of FDM parameters for improving part quality, productivity and sustainability of the process using Taguchi methodology and desirability approach. Prog. Addit. Manuf. 2020, 5, 59-65. [CrossRef]

30. Babu, N.V.; Venkateshwaran, N.; Rajini, N.; Ismail, S.O.; Mohammad, F.; Al-Lohedan, H.A.; Siengchin, S. Influence of slicing parameters on surface quality and mechanical properties of 3D-printed CF/PLA composites fabricated by FDM technique. Mater. Technol. 2021, 1-18. [CrossRef]

31. Di Angelo, L.; Di Stefano, P.; Dolatnezhadsomarin, A.; Guardiani, E.; Khorram, E. A reliable build orientation optimization method in additive manufacturing: The application to FDM technology. Int. J. Adv. Manuf. Technol. 2020, 108, 263-276. [CrossRef]

32. Salmi, M.; Ituarte, I.F.; Chekurov, S.; Huotilainen, E. Effect of build orientation in 3D printing production for material extrusion, material jetting, binder jetting, sheet object lamination, vat photopolymerisation, and powder bed fusion. Int. J. Collab. Enterp. 2016, 5, 218-231. [CrossRef] 
33. Buj-Corral, I.; Domínguez-Fernández, A.; Durán-Llucià, R. Influence of Print Orientation on Surface Roughness in Fused Deposition Modeling (FDM) Processes. Materials 2019, 12, 3834. [CrossRef]

34. Dezaki, M.L.; Ariffin, M.K.A.M.; Ismail, M.I.S. Effects of CNC Machining on Surface Roughness in Fused Deposition Modelling (FDM) Products. Materials 2020, 13, 2608. [CrossRef]

35. Suteja, T.J.; Soesanti, A. Mechanical Properties of 3D Printed Polylactic Acid Product for Various Infill Design Parameters: A Review. J. Phys. Conf. Ser. 2020, 1569. [CrossRef]

36. Ćwikła, G.; Grabowik, C.W.; Kalinowski, K.; Paprocka, I.; Ociepka, P. The influence of printing parameters on selected mechanical properties of FDM/FFF 3D-printed parts. IOP Conf. Ser. Mater. Sci. Eng. 2017, 227. [CrossRef]

37. Moradi, M.; Meiabadi, S.; Kaplan, A. 3D Printed Parts with Honeycomb Internal Pattern by Fused Deposition Modelling; Experimental Characterization and Production Optimization. Met. Mater. Int. 2019, 25, 1312-1325. [CrossRef]

38. Camargo, J.C.; Machado, R.; Almeida, E.C.; Silva, E.F.M.S. Mechanical properties of PLA-graphene filament for FDM 3D printing. Int. J. Adv. Manuf. Technol. 2019, 103, 2423-2443. [CrossRef]

39. Dudescu, C.; Racz, L. Effects of Raster Orientation, Infill Rate and Infill Pattern on the Mechanical Properties of 3D Printed Materials. Acta Univ. Cibiniensis 2017, 69, 23-30. [CrossRef]

40. Podroužek, J.; Marcon, M.; Ninčević, K.; Wan-Wendner, R. Bio-Inspired 3D Infill Patterns for Additive Manufacturing and Structural Applications. Materials 2019, 12, 499. [CrossRef]

41. Ahn, S.; Montero, M.; Odell, D.; Roundy, S.; Wright, P.K. Anisotropic material properties of fused deposition modeling ABS. Rapid Prototyp. J. 2002, 8, 248-257. [CrossRef]

42. Dave, H.K.; Patadiya, N.H.; Prajapati, A.R.; Rajpurohit, S. Effect of infill pattern and infill density at varying part orientation on tensile properties of fused deposition modeling-printed poly-lactic acid part. Proc. Inst. Mech. Eng. Part C J. Mech. Eng. Sci. 2019, 235, 1811-1827. [CrossRef]

43. Burke, C.; Dalal, A.; Abukhalaf, A.; Noorani, R. Effects of process parameter variation on the surface roughness of polylactic acid (PLA) materials using design of experiments (DOE). IOP Conf. Ser. Mater. Sci. Eng. 2020, 897. [CrossRef]

44. Yadav, P.; Sahai, A.; Sharma, R.S. Strength and Surface Characteristics of FDM-Based 3D Printed PLA Parts for Multiple Infill Design Patterns. J. Inst. Eng. 2020, 102, 197-207. [CrossRef]

45. Dezaki, M.L.; Ariffin, M.K.A.M. The Effects of Combined Infill Patterns on Mechanical Properties in FDM Process. Polymers 2020, 12, 2792. [CrossRef]

46. Samykano, M.; Selvamani, S.K.; Kadirgama, K.; Ngui, W.K.; Kanagaraj, G.; Sudhakar, K. Mechanical property of FDM printed ABS: Influence of printing parameters. Int. J. Adv. Manuf. Technol. 2019, 102, 2779-2796. [CrossRef]

47. Gopsill, J.A.; Shindler, J.; Hicks, B.J. Using finite element analysis to influence the infill design of fused deposition modelled parts. Prog. Addit. Manuf. 2017, 3, 145-163. [CrossRef]

48. Heidari-Rarani, M.; Ezati, N.; Sadeghi, P. Badrossamay Optimization of FDM process parameters for tensile properties of polylactic acid specimens using Taguchi design of experiment method. J. Thermoplast. Compos. Mater. 2020. [CrossRef]

49. Afrose, M.F.; Masood, S.H.; Iovenitti, P.; Nikzad, M.; Sbarski, I. Effects of part build orientations on fatigue behaviour of FDM-processed PLA material. Prog. Addit. Manuf. 2015, 1, 21-28. [CrossRef]

50. Galantucci, L.M.; Lavecchia, F; Percoco, G. Experimental study aiming to enhance the surface finish of fused deposition modeled parts. CIRP Ann. 2009, 58, 189-192. [CrossRef]

51. Gohar, S.; Hussain, G.; Ali, A.; Ahmad, H. Mechanical performance of honeycomb sandwich structures built by FDM printing technique. J. Thermoplast. Compos. Mater. 2021. [CrossRef]

52. Guessasma, S.; Belhabib, S.; Nouri, H. Effect of printing temperature on microstructure, thermal behavior and tensile properties of 3D printed nylon using fused deposition modeling. J. Appl. Polym. Sci. 2020, 138. [CrossRef]

53. Garlotta, D. A Literature Review of Poly(Lactic Acid). J. Polym. Environ. 2001, 9, 63-84. [CrossRef]

54. Keleş, Ö.; Blevins, C.W.; Bowman, K.J. Effect of build orientation on the mechanical reliability of 3D printed ABS. Rapid Prototyp. J. 2017, 23, 320-328. [CrossRef]

55. Ingole, D.S.; Deshmukh, T.R.; Kuthe, A.M.; Ashtankar, K.M. Build orientation analysis for minimum cost determination in FDM. Proc. Inst. Mech. Eng. Part B J. Eng. Manuf. 2011, 225, 1925-1938. [CrossRef]

56. Raju, K.V.M.K.; Janardhana, G.R.; Kumar, P.N.; Rao, V.D.P. Optimization of cutting conditions for surface roughness in CNC end milling. Int. J. Precis. Eng. Manuf. 2011, 12, 383-391. [CrossRef] 